http://dx.doi.org/10.12795/PH.1992.v07.i01.14

\title{
LA PERDIDA DE IDENTIDAD EN LA OBRA DE MALEK HADDAD
}

Leonor Merino

A feeling of misplace, a loss of national identity, due to the French colonisation, can be observed in the works of Malek Haddad. The literary development of the motive by this author is examined in this paper.

\section{LA NOVELA MAGREBI}

La literatura magrebí contemporánea después de la Segunda Guerra Mundial posec sus críticas y sus exegetas. Uno se admira por la gran cantidad de artículos y de estudios publicados desde hace ya unos años ${ }^{1}$.

Desde una perspectiva francesa, se ha dado prueba de una benevolencia y de cierta buena voluntad que, a posteriori, ha llegado a asombrar. No hay más que recordar el clima político de la época, en particular durante la guerra de Argelia.

$\mathrm{Si}$, en este aspecto, la izquierda francesa no dejó de expresar su simpatía o de aportar su apoyo efectivo a los movimientos de liberación, no supo, sin embargo, qué postura tomar para justificar este apoyo en el plano cultural. Había que dejar bien sentado que las socicdades colonizadas no salían de la nada, que estaban dotadas de valores auténticos y de una verdadera cultura.

1 Littéruture maghrébine de langue franģase. Introduction géntérale et auteurs, Sherbrooke. A. Naaman, 1973, 496 p. $2^{\circ}$ édit. revue et corrigée $1978 ; 3^{\circ}$ édit. 1980. 
La visión del «homo arabicus» limitado, avejentado, paralizado por su determinismo, interpretado «esencialmente» por su comportamiento religioso, no satisfacía ya a la izquierda francesa. Se puede decir que los primeros escritores magrebíes de expresión francesa después de la segunda guerra, han sido para esta izquierda, verdadera tabla de salvación. Así hay que comprender el interés que suscitaron; su presencia colmaba un vacío y respondía a una esperanza. Se acogió con cierto entusiasmo a esta literatura que fue acaparada por las editoriales, de tal forma, que cada una de éllas poseía su «árabe de servicio». A este respecto Malek Haddad declara con sensible lucidez:

«Nous sommes les tristes bénéficiaires d'une actualité boulcversée et bouleversante»².

Para el escritor magrebí, era la única posibilidad de resurgir. Sin embargo, se trataba de una opción peligrosa. Actualmente, siendo otra la coyuntura mundial, «resuelto» el problema nortcafricano, algunos escritores magrebíes de lengua francesa experimentan el sentimiento de haber sido utilizados.

Las críticas procedentes de la derecha, por otra parte, no siguieron el movimiento favorable de esta joven literatura. Robert Kemp se indignaba cándidamente contra la ingratitud de Mohammed Dib, a quien no permitía que «insultara» a los franceses en su propia lengua.

He aquí la respuesta de Memmi -gran intelectual y humanista entre estos escritoresa propósito de este problema:

«On s'est étonné de l'apreté des premiers écrivains colonisés. Oublientils qu'ils s'adressent au même public dont ils empruntent la langue? Ce n'est pourtant ni inconscience, ni ingratitude, ni insolence. A ce publique précisément, dès qu'ils osent parler, que vont-ils dire sinon leur malaise et leur révolte"? Espérait-on des paroles de paix de celui qui souffre d'une longue discorde"?...»?

Considerando nuestro análisis ahora, desde una perspectiva magrebí, hay que reconocer en estos escritores una verdadera voluntad de clarificar sus posturas y de sobrepasar el estadio de su aculturación. Estaban convencidos de su misión y de su mensaje. Deseaban dar a conocer el drama de una sociedad en crisis. Más aún, habían comprendido que encarnando una situación dada, podían manifestar la transformación profunda llevada a cabo por la descolonización, y converger de esta forma en los temas siempre de actualidad, la alienación, la despersonalización, el cruce de culturas, y la marginación.

En este sentido, estos escritores han triunfado. Incluso admitiendo que sólo algún contexto de esta literatura ha cubierto su tiempo, ya no se puede negar, que forma parte de la cultura universal. 
Sin embargo, la crítica de la literatura magrebí realizada incluso por los mismos interesados no ha despejado todos los malentendidos. Escritores, críticos autóctonos, escritores franceses de derecha o de izquierda, todos, estaban de acuerdo sobre el papel y el alcance de esta literatura que debía ser ante todo un testimonio de la literatura norteafricana. Y es que con frecuencia hacemos que la escritura dependa de su fuerza testimonial y de su realismo.

Más que nunca, esta escritura es la desconocida que es preciso afrontar y descifrar. Se trata de «instalarse» en el interior de la obra y de retirar la estructura que conforma el escrito literario. Pero la mejor manera de comprender esta problemática y al hombre magrebí, es leyendo su obra, su literatura.

Literatura de llamamiento sincero al cambio, vínculo entre lo mejor del Occidente y del Oriente, de la misma forma que el arte plástico y la canción popular, contribuye ampliamente a la revalorización del patrimonio cultural magrebí.

En esta literatura la presencia del fenómeno francés en la obra de numerosos escritores de expresión francesa se manifiesta, además del empleo del aparato lingüístico francés, por el sentimiento del desarraigo personal de tunecinos, argelinos o marroquíes frente a su terruño natal. Se debe, claro está, a la presencia colonial de Francia en el Magreb. La problemática del «yo», itinerante, desarraigado en el plano étnico, social, cultural, religioso y nacional, constituye, casi siempre, el punto temático de partida en la obra de estos escritores en cuestión.

\section{MALEK HADDAD}

Nació el 5 de julio en Constantine (Argelia), dejó sus estudios, que estaba realizando en la Facultad de Derecho en Aix-en-Provence, para dedicarse a la literatura. En 1955, teniendo que exiliarse, marcha a Francia relacionándose con personalidades literarias. Trabaja durante al gún tiempo como profesor, más tarde, comparte con el escritor argelino Kateb Yacine la situación de los trabajadores agrícolas de Camargue, sin haber abandonado nunca su obra literaria ${ }^{4}$. Conseguida la independencia en Argelia, regresa a su patria donde trabajó en el Ministerio de Asuntos Culturales.

Al estudiar la obra de Malek Haddad, se observa que cl fenómeno francés reviste un carácter cspecial. De igual forma que el tunecino Albert Memmi o el cabila Mouloud Feraoun, Malek Haddad está, también, marcado por Francia y se podría decir que es consciente del desarraigo en su calidad de escritor, que lo concibe como un drama sobre

4 - Le Malheur en danger (poesia), Paris, La Nef de Paris 1956.

- La Derniere impression (novela), Paris, Juillard 1958.

- Je loffrimat une gazelle (novela), Paris, Juillard 1959.

- L'élève et la lesom (novela), Paris, Juillard 1960).

- Ecoute et je tappelle (poemas precedidos de Les zéros tournent en rond), Paris. François Maspéro 1961.

- Le Qua aux Fleurs ne répond plus (novela). Paris, Juillard 1961. 
todo en el dominio de la educación, y en el conjunto de la vida cultural en Argelia. Pero lo que abruma el espíritu del escritor, más aún que la influencia francesa durante la colonización y tras la independencia, es el analfabetismo de su país, la ausencia de un público de lectores. Malek Haddad, no es un extraño en su tierra, sino que ha sido arrancado a la fuerza de su original contexto lingüístico:

«Ces mots que je savais

lorsque j'étais berger»

La poesía de Haddad, así como su prosa, son las variantes de este doloroso punto de partida para el autor. A menudo, lo trata bajo forma de temas amorosos, o bien analiza las actitudes personales con respecto a Argelia o a Francia, $\mathrm{c}$ incluso expone el problema con una reflexión interior que se plantea su personaje, y que le lleva a considerar lo urgente del compromiso en favor de Argelia dentro de unas circunstancias históricas concretas.

Los temas citados están presentes en casi todas sus novelas. Es cierto que cada uno de ellos forma un conjunto en el plano del contenido y de la forma, sin embargo, no representan más que una parte de un mundo mucho más amplio en la obra de este escritor. La unidad de este mundo está fijada por la relación Argelia-Francia. La guerra por la independencia argelina es el contexto histórico, directo o indirecto, de toda la obra de Malek Haddad.

Los hilos épicos tienen, incluso en el marco de una sóla novela, una cantidad de variantes, los problemas se presentan con frecuencia en función de la sicología de los personajes. Al lado de la cronología, el autor recurre a los monólogos interiores que exigen una retrospectiva y suprimen la cronología, favoreciendo, por otra parte, el empleo del elemento poético en la prosa.

Las razones expuestas tanto por el contenido como por la forma exigen una aproximación específica a la obra de Malek Haddad. Por eso el reflexionar sobre sus novelas, se convierte en una necesidad que nos permitirá extraer el punto de partida temático de la obra de este escritor, y el papel que el elemento francés juega en ella.

\section{ARGelia y Francia}

La guerra de Argelia es, como se ha dicho, el principal contexto histórico en el conjunto de la obra de nuestro escritor. La relación planteada entre los dos países va a ser contradictoria y se plantea en distintas variantes.

Se puede decir, a primera vista, que Argelia, en guerra, está ausente en la novela Je t'offrirai une gazelle. Dos africanos, Moulay y Yaminata se aman en un oásis al borde del desierto cada vez que el héroe pasa por allí con su camión. La gacela viva que Moulay promete a su bien amada es, también, algo concreto que forma parte de este medio idílico. 
Este desierto en algún lugar de Argelia no es sin embargo el único marco en la novela. Paralelamente está París y el autor de una novela, probablemente argelino, Gisèle Duroc, una francesa que trabaja en una editorial intentando que se publique esta novela. Simultánea a la historia africana, en París, nace igualmente el amor entre el autor-narrador y Giséle. La analogía se refleja hasta en la promesa del futuro regalo, que es también una gacela, pero no viva, sino de paja que han visto en un escaparate parisino.

A penas se habla de la guerra. El vínculo entre los dos mundos es a la vez el narrador y un personaje de la novela, un argelino que vive en Francia. Sobre su persona recae, ante todo, el sentimiento de injusticia colonial. Las palabras aparentemente más comunes, evocan con dureza una serie de asociaciones que no se detienen más que ante la palabra «guerra».

«-Tes papiers...

Il ne faut pas tutoyer un homme. Parce qu'ensuite ça va très loin, très loin. La torture commence par le tutoiement» ${ }^{6}$.

Moulay, también sabe lo que quiere decir ser árabe; el Sahara se lo recuerda:

«Le Sahara, je le connais. J'ai farfouillé tous les recoins, tous les replis cachés de la nuit. Je sais l'injure, l'affront, la haine. Je n'ai pas répondu. J'ai regardé le désert. J'ai répondu par le désert. J'ai vu trop de mediants, j'ai vu trop de mouches. Le trachome a menacé chacun de mes regards. J'ai vouvoyé, on m'a dit: tu. Je suis un Arabe, c'était devenu un métier. J'ai compris le maigre rictus de la famine. J'ai compris le froid et la chaleur. A l'école, au régiment, j'ai su l'injure, l'affront, la haine. Je suis un Arabe, c'était devenu une malédiction» ${ }^{7}$.

Los dos ambientes paralelos, el del desierto africano y el ciudadano parisino, se conjugan por la imagen del desierto, en un sentido concreto como figurado. El marco concreto del Sahara permite el empleo de una rica poética:

«La piste a retrouvé le chemin des étoiles. Seules les étoiles ont assez de patience. Rien ne supporte le désert. Les oiseaux n'en veulent pas. Les gazelles l'évitent. Et les coquilles brisées des oeufs d'autruche sont les vestiges d'on ne sait quelle fuite d'apocalypse. Les chameaux sont morts. Les mirages, désespérément, se ressemblent. Ils évoquent des îles, des îles en chapelet, archipels taciturnes. Pourtant la piste a retrouvé le chemin des étoiles» ${ }^{R}$.

París, desde un cierto aspecto, hace pensar también en el desierto. El desierto en París, es el vacío, el silencio en las relaciones humanas. La proximidad de los dos lugares queda marcada por cl símbolo de la gacela, deseo de libertad que subyace en el espíritu de la 
conciencia argelina en ese puntual momento de su historia. La gacela, no es una quimera, sino símbolo de un objetivo, de un fin que hay que lograr.

La novela La Dernière impression no trata de ambientes paralelos, sino, al contrario, de una fuerte oposición entre dos países en guerra. Bouzid, el hermano del personaje principal, se ha unido, recientemente, al maquis. Este corto relato es el contexto histórico de la novela que da impulso a la vez a la acción. Sólamente al final de la obra, el autor expondrá el combate armado entre argelinos y franceses.

La oposición entre los dos países queda marcada por el símbolo que representa el puente que Sä̈d, joven ingeniero argelino, ha construído y que deberá ser destruído en este marco de encarnizada lucha contra los franceses. Para Saïd, es doloroso ver destruir su propia obra; pero a lo largo de la novela el héroe camina hacia una actitud consciente y comprometida en favor de la lucha abierta contra el enemigo. El valor simbólico del puente queda subrayado por el imaginario vínculo que ofrecía entre estos dos países.

Malek Haddad no interpreta la guerra de Argelia sólo como un conflicto político entre colonizador/colono, aunque sea ćste el núcleo de su interés, sino que lo ve integrado en la lucha contra la opresión y la injusticia, en muchos rincones del mundo, en Chipre, Vietnam, Malasia.

La obra culmina con la descripción del combate armado. Para introducirnos en el ambiente de la obra, Haddad recurre a la oposición entre la imagen que ofrece la paz y la guerra. Al infortunio en el mundo, se oponen los juegos idílicos de los niños en el jardín del Castillo de los papas de Avignon, las citas de jóvenes enamorados, los minutos de solaz ante una simple taza de té. Inmediatamente, contrasta el dolor de una viuda, la marginación de un estudiante negro expulsado de la escuela, en algún lugar de Estados Unidos, un superviviente ocultándose en Nicosia... Este corto capítulo que constituye una especie de prólogo a la escena del combate, comienza y termina con una indicación de tiempo que tiene, también, como finalidad introducir la oposición principal entre la guerra y la paz en el mundo:

"Ailleurs aussi il peut être quatre heures ou cinq heures del'après-midi»". «Il peut être quatre ou cinq heures de l'après-midi, n'importe où sur la terre... ${ }^{10}$.

Al lado de la fuerza empleada en favor de la lucha del pueblo, el autor describe lo absurdo de esta matanza entre los hombres a quienes se les obliga a tomar partido. En muchas ocasiones, en Haddad, se encuentra como denominador común para franceses y para argelinos, que las cosas más simples, las más triviales están llenas de poesía: un tomillo, una hormiga:

«On attend. L'avion vole plus bas.

Derrière d'autres rochers, d'autres hommes attendent. Il se peut qu'un Saïd

" La Dernière impression. pág. 191.

10 Ibid. pág. 192. 
qui s'appellerait Jacques ou Lucien regarde au même instant un brin de serpolet, un escargot, une fourmi»" ${ }^{\prime}$.

Unos minutos antes de que comience el combate, Saïd, Bouzid y Rachid miran hacia atrás recordando los momentos más felices de su vida, contrastándolos con la lucha que comienza:

«Je t'aime depuis que je suis toute petite.

Une écharpe: moments chauds de la paix sur la maison tranquille. C'était la mère que l'avait tricotéc. Une maille à l'endroit, une maille à l'envers. Le tic-tac sempiternel du réveil sur le buffet de la cuisine.

... Le père revient de la ville, la grille a grincé. Il distribue aux gosses des cornets de pois chiches de caramels» ${ }^{12}$.

Toda la tensión del combate se concentra en la completa armonía entre Bouzid y Saïd. Los gestos, las miradas aunadas, ensambladas. La lucha, Haddad la traslada a las actividades diarias cuando había paz, por ejemplo en una lección de cálculo en la escuela:

«Aujourd'hui, elle est là, la opération, la soustraction. Elle est là, en chair et en os. Moins Rabah, moins Rachid, moins Brahim, moins Djamel...

MOINS L'ALGERIEN UNTEL $\gg^{13}$.

La ausencia de Bouzid es dolorosa para la familia, ciertamente, pero lo que en realidad predomina, es el orgullo de ver a un miembro de ésta reunirse con el maquis. Por lo que se refiere a los franceses, en una actitud negativa, el entorno familiar, por boca de una anciana, en su lecho de muerte, deja bien claro a su nieta que espera un hijo, que ni ella ni su vástago serán aceptados en el seno de la familia árabe:

«- Tu attends un enfant? Tu l'appelleras François et il ira à l'école à Paris.... ${ }^{14}$.

Sin embargo, la misma anciana mujer declara, orgullosa, hablando de sus hijos:

«-Tous, ils sont tous dans la montagne.

Elle avait dit ces mots avec la même fierté qu'elle eût dit:

ils sont partis en pèlerinage à La Mecque» ${ }^{15}$.

La decisión de Saïd madura a lo largo de diversos contactos con los argelinos cuya apacible vida en la colonia francesa ha sido dolorosamente alterada por la guerra:

«Pour Chérif, le bonheur consistait dans ce que l'on a perdu. La paix, le voyage en France tous les deux ans, les prises de position qui n'engagent à rien et les verbiages doucereux à la sauce humaniste ${ }^{16}$.

\footnotetext{
Ibid. pág. 188.

Ibid., pág. 196.

Ibid. págs. 201-202.

Ihicl., pág. 41.

Ibid., pág. 39

Ibid. pág. 39
} 
Chérif ve como única salida a la situación, el desplazarse a Francia con toda la familia. El único obstáculo que se plantea es la negativa de su mujer Leila, hermana de Saïd. Este y Chérif se encuentran en un viejo lavadero donde la familia guarda los objetos ya inservibles. Malek Haddad, antes de que comience la conversación entre los dos hombres, da vida en su descripción a todos los viejos objetos, una rueda de carretilla, un cuadro ya oxidado de una bicicleta, una vieja cocina, etc., relacionándolos con los miembros de la familia, mostrando la íntima relación entre ese batiborrillo del corazón y del espíritu, y la vida del hombre y de la tierra. Y es tras esta descripción cuando las frases de Chérif, ante su decisión de emigrar, no se comprenden:

«- Ta soeur ne me parle plus...

... Elle ne veut pas me suivre. Nous n'avons plus rien à faire ici... Là-bas, au moins, on pourrait avoir la paix... ${ }^{17}$.

Saïd no responde directamente. Su silencio da muestra de no compartir este deseo, acalla su monólogo interior en el que su actitud, frente a la de Chérif, adquiere mayor convicción. El soliloquio de Saïd lo señala la esencia de las cosas que simbolizan su identidad:

«Lui dire:

Mon pauvre vieux, tu es comme cet abricotier qu'on perçoit de la petite lucarne de la buanderic. Tu es mort. Mais alors que l'arbre est devenu du bois à la fin de l'hiver, toi, c'est à l'orée du printemps que tu te condamnes irrémédiablement à l'automne à perpétuité.

...En quelque sorte l'abricotier a rempli sa mission.

...Tu vas partir dans les pays où «le gens au creux du lit font des rêves». Oui, l'automne à perpétuité. Ce vieux cadre de bicyclette, cette roue de la brouette, ces arraignées qui tissent le souvenir, cette jarre qui contint de l'huile, et ce bric-à-brac du coeur et de l'esprit, tous ces trésors pour les gosses ct pour les hommes ne te parlent pas» ${ }^{1 \mathrm{x}}$.

Los monólogos de Saïd son numerosos. Los provoca siempre un reencuentro, un diálogo, un planteamiento. La decisión que debe tomar se vuelve cada vez más complicada puesto que está marcada por el amor que siente por Lucía, maestra francesa en Argelia, decidida, a pesar de todo, a regresar a su patria, y que mucre víctima de una lucha callejera, la víspera de marcharse a Francia. Este amor recíproco, perdido ya para siempre, confirma el lado trágico de la relación de estos dos jóvenes, que sin quererlo encarnan los dos polos opuestos de la guerra. Saïd siente amistad por los franceses que no desean la guera, pero sobre la tumba de la amada en Aix-en-Provence, dice:

«-Mais, par la vertu de ton sommeil, j'ai retrouvé mes rêves et je veux te venger de cette balle perdue qui m'a fait te perdre, et je veux te venger de cette guerre qui m'a enlevé la paix» ${ }^{19}$. 
Saïd en esta ciudad francesa se encuentra con compatriotas que viven marginados, despreciados, realizando los trabajos más duros:

«Il y a quelque chose l'héroïque dans leur présence. Ils vivent-c'est une façon de parler- chez ceux qui les méprisent. Chez ceux qui les fuient. Alors ils vivent -c'est une façon de parler-entre eux. La même cargaison de malheur. Déracinés. Transplantés. Ils vivent.

...Ils étaient chez ceux qui les ecceptent dès lors qu'ils passent inaperçus.

Or, en vérité, est-il possible qu'un Nord-Africain puisse passer inaperçu en France, en Suisse ou dans la lune? Le malheur peut-il passer inaperçu?» ${ }^{20}$.

Saïd constata que muchos argelinos van a Francia con el fin de resolver su situación económica, pero allí estos «orphelins de leur patrie» viven en condiciones miserables, en los barrios más pobres de las «civilizadas» ciudades francesas. Viéndoles con toda su miseria, decide formar parte activa en esta marginación.

En una pequeña tasca en Aix-en-Provence, a lo largo de una conversación mantenida con un pintor desconocido, Saïd decide «faire quelque chose»:

«-Et vous, qu'est-ce que vous faites dans la vie?

... Saïd mit du temps à répondre.

- dans la vie, qu'est-ce que je fais? Je ne fais rien. Et ça m'emmerde.

On regarde, on écoute, on prend des notes que l'on conserve dans les yeux, dans les oreilles.

On ne fait rien. C'est ce qu'on a de commun avec les morts, ne rien faire.

- Ne rien faire, c'est ça le malheur» ${ }^{21}$.

He aquí a bordo de un barco entre Marsella y Argelia, Saïd toma una decisión definitiva:

«Il ne rentrerait pas en Algérie pour prendre un tram, pour acheter un journal, pour embrasser sa mére. Il rentrerait en Algérie pour faire quelque chose...

Et c'est un signe des temps qu'en Algérie, comme ailleurs, pour un algérien, il y a toujours quelque chose à faire $»^{22}$.

Saïd reconociendo que el carácter primordial de la lucha por la independencia de Argelia, es el deber de participar en ella, mucre en la barricada. En ese instante, Malek Haddad, le ofrece la visión de una Argelia liberada al día siguiente de la guerra, y ésta, scrá la última impresión del héroe. 


\section{Conclusión}

El problema del desarraigo nacional se plantea en la obra de Malek Haddad de forma indirecta. No surge más que como tela de fondo de la situación concreta de Argelia, de la doliente situación con relación a la potencia colonizadora en el momento de la guerra. Todos los problemas personales de los héroes de Haddad están condicionados por el conflicto franco-argelino, se podría incluso decir que la lucha está, en la mayoría de los casos, llevada al espacio interior de los personajes. Malek Haddad habla igualmente de los argelinos comprometidos directamente en ella, en el maquis o en el mismo ejército. Esta mención un tanto marginal, introduce con frecuencia el conflicto sicológico, cuya existencia está aún más ligada a la guerra.

El autor descubre que el desarraigo se ha producido en la conciencia de sus personajes, ante todo, como fruto de la enscñanza francesa que han recibido. El héroe en su errancia está ligado al conjunto de la situación de los dos países. No se contenta sólo con plantear el problema, intenta una solución que, ciertamente. lejos de ser definitiva, reviste una importancia no desdeñable: sólo el acto comprometido en favor de una Argelia independiente puede contribuir a lograr erradicar el sentimiento de desarraigo que continuará manifestándose, por otra parte, durante un cierto tiempo incluso después de la independencia.

Con relación a otros escritores que abordan, también, el tema de la itinerancia, de la pérdida de raíces, como el tunecino Albert Memmi, Malek Haddad viendo el problema en su contexto real, sin aportar soluciones absolutas o esquematizadas, ve el desarraigo en su relación individuo-sociedad, luego, lo moldea en el contexto así definido. En este acto comprometido, el autor quiere lograr la esperanza de ver, más tarde, perdido ya para siempre, este doloroso desgarro. 